\title{
Genomic tools for traceability: Opportunities, challenges and perspectives for the Canadian forestry sector
}

\author{
by Julie Godbout ${ }^{1 *}$, Claude Bomal ${ }^{1}$, Ken Farr ${ }^{2}$, Miranda Williamson ${ }^{3}$, Nathalie Isabel ${ }^{1}$
}

\begin{abstract}
Consumers, retailers, investors, and governments want quality products that are both safe and obtained through legal and sustainable practices. The solution put into place to meet those challenges requires the implementation of a traceability system. In the context of forestry, traceability is the ability to inform about the identity or provenance of a wood product. The principle of traceability helps establish trust among the various stakeholders throughout the value chain. To this day, most traceability systems are based on paper permits, which are easier to falsify than systems that are based on genetic markers. In this manuscript, we define the elements of a traceability system based on genomic tools that could be useful for the Canadian forest sector. We also present several examples in which genomic tools are or could be used as traceability systems. Genomic tools and data happen to be available in quantity for several forest species and they could constitute the basis for the development of such traceability systems. Our aim is to demonstrate that there are actually great opportunities to develop such systems that could be applied to the Canadian forest sector.
\end{abstract}

Keywords: traceability, genomic, markets, certification, sustainability, urban forestry, quality control, value chain, taxonomy, origin, database

\section{RÉSUMÉ:}

Les consommateurs, les détaillants, les investisseurs et les gouvernements veulent des produits de qualité, sécuritaires et qui résultent de pratiques légales et durables. Les principes de la traçabilité permettent de répondre à ces différents enjeux. Dans le contexte forestier, la traçabilité est la capacité d'informer sur l'identité ou la provenance d'un produit du bois. Ce principe aide à établir la confiance entre les différents acteurs de la chaine de valeur. À ce jour, la plupart des systèmes de traçabilité sont basés sur des permis en papier qui sont facilement falsifiables. Dans ce manuscrit, nous définissons les éléments d'un système de traçabilité basé sur des outils génomiques qui pourrait être utile pour le secteur forestier canadien. Nous présentons aussi plusieurs exemples de la façon dont les outils de la génomique sont ou pourraient être utilisés. Des données et des outils génomiques sont actuellement disponibles en grandes quantités pour plusieurs essences forestières et ceux-ci pourraient constituer la base du développement de tels systèmes de traçabilité. Notre objectif est de démontrer qu'il y a actuellement de grandes opportunités pour développer de tels systèmes qui pourraient s’appliquer au secteur forestier canadien.

Mots-clé: traçabilité, génomique, marchés, certification, développement durable, foresterie urbaine, contrôle de la qualité, chaîne de valeur, taxonomie, origine, base de données

\section{Introduction}

The concept of traceability dates back to the 1930s when it was used to promote the high quality of wines from France's Champagne region (CIVC 2011). In the wake of food supply chain scandals such as chicken dioxin contamination in Belgium (Bernard et al. 2002) and mad cow disease in the United Kingdom (Wales et al. 2006), traceability really began to draw large public attention by becoming a powerful tool proposed by authorities to protect consumers (European Parliament 2002). In addition, the endorsement of the traceability concept was certainly stimulated by the emergence and development of new markets relative to "fair trade" products. As a consequence, various goods (coffee, cacao, cotton, as well as wood) are now sold to consumers with the promise that their production and distribution meet sustainable development criteria (UN Global Compact and BSR 2014). In response to public and world market demands, the forestry sector efficiently endorsed this "fair trade product" principle by adopting different forest certification systems (NRCan 2017). Forest certification is now accepted as a golden standard that largely guarantees sustainably-grown, responsibly-harvested and legally-traded forest products. The forest certification principle, since it informs about practices related to the harvesting of trees, is similar to a system of traceability. Indeed, it tells about the origin of a wood product which gives it an additional value that is extrinsic, that is to say it is not linked to observable attributes (such as wood appearance or durability).

\footnotetext{
${ }^{1}$ Natural Resources Canada, Canadian Forest Service, Laurentian Forestry Centre, 1055 du P.E.P.S., Stn. Sainte-Foy, P.O. Box 10380, Québec, QC, G1V 4C7, Canada * corresponding author: julie.godbout.1@gmail.com

${ }^{2}$ Natural Resources Canada, Canadian Forest Service, Science Policy Integration Branch, 580 Booth Street, Ottawa, Ontario, K1A 0E4, Canada.

${ }^{3}$ Natural Resources Canada, Canadian Forest Service Trade, Economics and Industry Branch, 580 Booth Street, Ottawa, Ontario, K1A 0E4, Canada.
} 
Whether the purpose is to comply with regulations, to guarantee sustainability or to secure market shares, the concept of traceability now helps to establish trust among the various stakeholders throughout the value chain. Two main criteria can be used to assess the quality of a traceability system: independence and reproducibility. Citing forest certification as an example, we could say that these systems meet the independence criterion as the certification processes are managed by an independent third party that checks the credibility of the label through verifications and audits. However, forest certification systems, albeit highly effective, are vulnerable to tampering as they mostly rely on a paper permit system which, by its nature, is non-reproducible. Forest certification systems currently in use have not been developed to ascertain the nature of a wood product. Consequently, prosecuting for illegal logging and associated trade, mislabelling of timber species or smuggling of wood products can only be supported by the development of robust tools and technologies that can infer the nature and origin of timber and wood products.

Technoscientific tools, such as genomic tools, provide reproducible results that are difficult to falsify. For example, genetic markers have uncovered cases of misidentification of fish and seafood in markets and restaurants (e.g., Logan et al. 2008; Khaksar et al. 2015). Such mislabelling cases may stem from human error or intentional deceit. Genomic tools therefore offer a reliable alternative to traditional identification, especially for processed products for which morphological criteria cannot be checked. These methods, of course, apply to all products in which the raw material is organic (living material).

In this article, we will first define the essential elements of a traceability system and present different theoretical approaches associated to the specific use of genomic tools in the forestry context. Second, we will demonstrate how a vast diversity of forestry-related questions, not exclusively related to illegal logging, could be answered with several examples where genomic tools are actually used to trace forest products. We will also discuss new areas where such tools could be applied in a near future to address traceability questions. Finally, we will highlight the perspectives and challenges associated with traceability in general as it is applied to the Canadian forest sector.

\section{What exactly is a traceability system?}

Traceability can be defined as "the ability to trace the history, application or location of an entity by means of recorded identifications" (ISO 1994). It thus implies tracing back a product or a few key ingredients at every stage of the supply chain (Fig. 1). In forestry, it refers more specifically to the 1) identity and/or 2) provenance of timber or wood products. By identity, we mean the taxonomical identification of the tree, which could present different degrees of precision corresponding to different genetic units: genera, species, subspecies, cultivars, varieties, or even a specific individual. By provenance, we generally refer to the geographic location where the tree would have grown, such as a country or a territory. In the latter case, and depending on the method used, this may also point to an ecological area such as a habitat rather than to a specific geographical region.

\section{Practical framework of a traceability system}

A traceability system should be developed in order to answer a specific and predefined question. Such an answer (identity and/or provenance, in the case of a tree as presented before) is obtained by using both mandatory elements that define the practical framework of a traceability system: a technoscientific tool and a reference database (Fig. 1). The context, in which the traceability system is thought to be applied, will determine the specific question and the degree of precision needed. Therefore, it is imperative that developers establish the capacity of the system to provide an answer (i.e., its resolution) before it can be used in a practical framework. Those limits will be dependent on the choice of tools, but also on the richness of the reference database. For each traceability system, equal importance should be given to the building of a complete database as to the validation of the tools. Their development should be conducted in parallel because the quality of the database will be dependent of the precision of the technoscientific tools.

\section{The technoscientific tools}

Different scientific or technical tools can be used to check the identity and/or the provenance of a living product. We can classify those tools into three categories based on the type of information they can provide: genomic, morphological and chemical (Table 1). Tools from these three different categories are not mutually exclusive, and they can be used in combination. Each category of tools has its own specific technical and practical characteristics that influence its ability to inform about the identity or the provenance of the products tested (for a complete review of the different techniques, see Dormontt et al. 2015).

Rationally, one of the first constraint in the establishment of a traceability system will be the cost for its development (tools and database) and its subsequent implementation (efficiency). In terms of development, genomic tools may have some advantages over chemical or morphological tools since a lot of resources are already available. In fact, the development of a traceability system could already benefit from the large-scale genome projects (e.g., Arborea, SmartForests, SpruceUp) that produced valuable genomic resources (DNA sequences and genetic markers) for several Canadian forest tree species (e.g., Pavy et al. 2013).

\section{The reference database}

For traceability purposes, genomic tools alone are inefficient. They have to come with an associated database that contains genomic data obtained from validated reference materials corresponding, for instance, to a particular tree species (i.e., its "identity"). A "good" reference database would thus include information relative to all potential species or individuals thought to be tested (e.g., species found in the same area, sister species).

These reference specimens are individuals for whom the identity and provenance are known and verified. Considering a database that could be applied to the forestry sector, they can be retrieved either from provenance trials, living collections of trees from different geographical origins (often repre- 


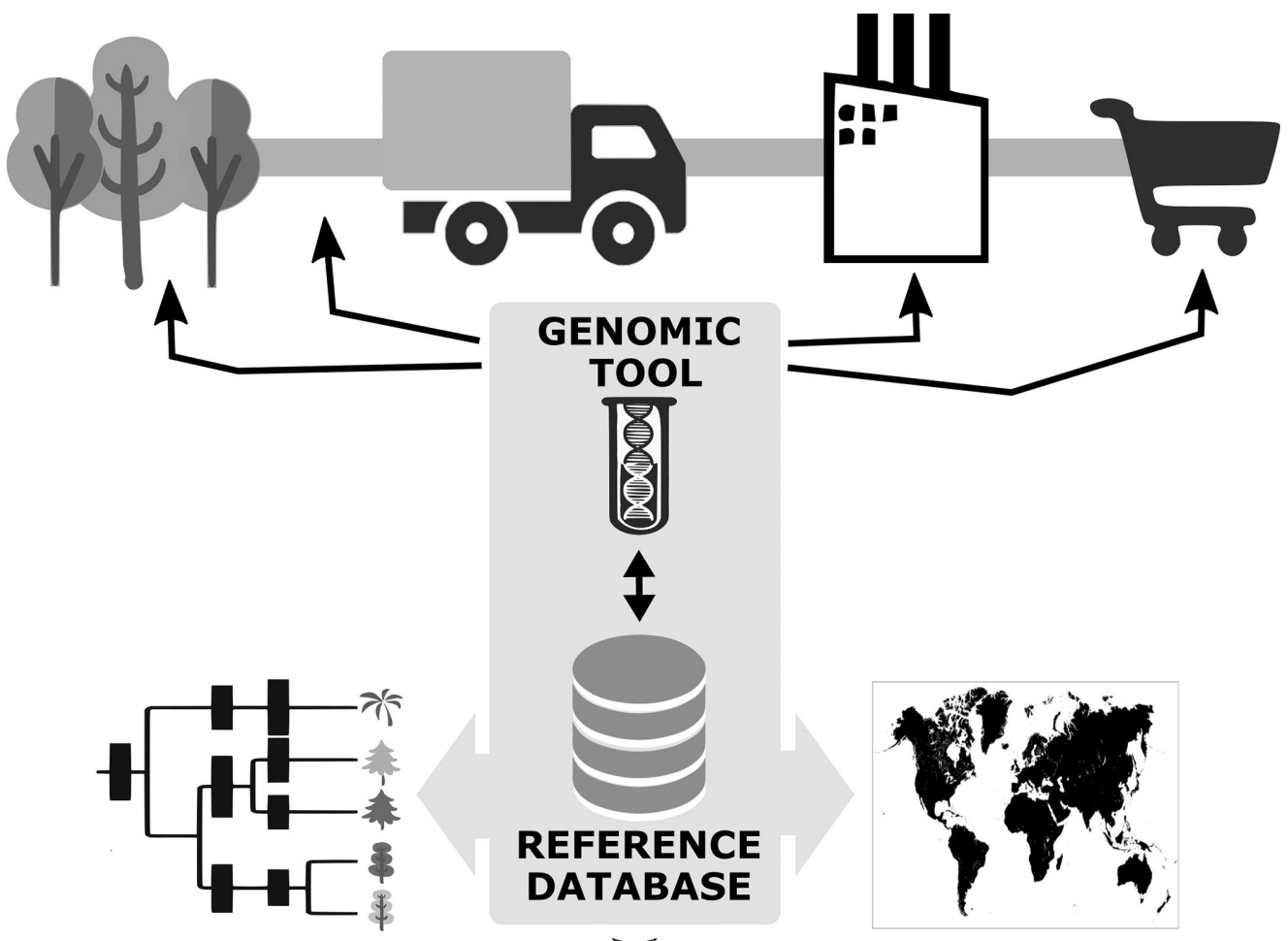

Identity

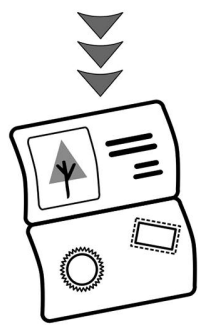

\section{Provenance}

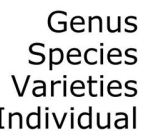

as

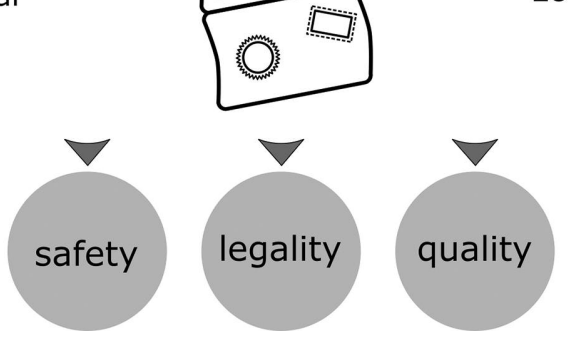

Continent

Country

Region

Ecosystem

Fig. 1. Representation of a traceability system and the information it can offer at different steps of the chain of custody as well as the taxonomical and/or geographical information it can provide at different resolution levels.

sentative of species' range and established in plantations, or from herbaria). In Canada many provenance trials for several commercial forest species have already been established by different forest departments (provincial and federal) for research and monitoring purposes since the 1950s.

To feed data into the database, the reference specimens must be analyzed with the genomic tools developed using a validated and standardized protocol; i.e., the same protocol that will be used at the time of using the traceability system with unknown specimens. Such standardization of the protocol will result in standardized data that can be easily compared with those of the reference database in order to answer the question asked.

Three approaches when using genomic tools in a traceability system

Depending on the question to be resolved, three main approaches, which correspond to different levels of resolu- 
Table 1. Different types of data that can be used to develop a forestry traceability system

\begin{tabular}{|c|c|c|c|}
\hline Type of data & Information given & Expertise and knowledge required & Data examples \\
\hline Genomic & $\begin{array}{l}\text { Identity: species, } \\
\text { subspecies, cultivar, } \\
\text { varieties, clonal line }\end{array}$ & $\begin{array}{l}\text { Low technical expertise is required if the process } \\
\text { is automated. At small scale, moderate to great } \\
\text { technical expertise is necessary to apply the } \\
\text { method / Low to moderate knowledge is required } \\
\text { to interpret the results }\end{array}$ & $\begin{array}{l}\text { DNA sequences, genotypes from all } \\
\text { types of markers (SNP, microsatellite, } \\
\text { genotyping by sequencing) }\end{array}$ \\
\hline Morphological & $\begin{array}{l}\text { Identity: species, } \\
\text { subspecies, cultivar, } \\
\text { varieties, clonal line }\end{array}$ & $\begin{array}{l}\text { Moderate technical expertise needed / Great } \\
\text { knowledge necessary to interpret the results }\end{array}$ & $\begin{array}{l}\text { Morphological characteristics of the } \\
\text { harvested wood or the standing trees: } \\
\text { colors, wood pattern, bark, bud, } \\
\text { flower, leaf } \\
\text { Dendrochronological data }\end{array}$ \\
\hline Chemical & $\begin{array}{l}\text { Provenance: geographical } \\
\text { region, ecosystems } \\
\text { \& Identity: } \\
\text { Species }\end{array}$ & Comparable to genomic data & $\begin{array}{l}\text { Isotopes } \\
\text { Metabolites (phenolic } \\
\text { compounds, terpenoids, fatty acids, } \\
\text { sugars, etc.) }\end{array}$ \\
\hline
\end{tabular}

tion, can be applied for traceability purposes (Fig. 2). They are: i) the fingerprinting approach, which differentiates individuals within the same species (refers to identity); ii) the taxonomic identification approach, which differentiates individuals belonging to different taxonomic units-genus, species or variety (also refers to identity); and, iii) the phylogeography approach, which identifies the geographic region of origin of an individual (refers to provenance).

The three approaches differ in the type of genetic markers used. Genetic markers are variable genomic regions that provide information allowing a distinction between individuals, species or individuals from different geographic regions. In the fingerprinting approach, markers allow the generation of a unique fingerprint for each individual in the traceability system. This is used in forensic sciences when an unidentified sample found at a crime scene is matched to a known individual (Gill et al. 1985; Jeffreys et al. 1985, 1988) whose fingerprint may be found in a database or which could be tested using the same set of markers. Uniqueness is a critical factor to take into account in order to avoid false positives (i.e., in the case of a unique fingerprint attributed to two members of the same family). The taxonomic identification approach uses genetic markers that vary little between individuals of a same species but show differences between species. This is the type of approach used in the Barcode of Life project, which aims to identify all species using one or more genomic regions (Hajibabaei et al. 2007; Ratnasingham and Hebert 2007). For some taxonomic groups, the Barcode project differentiates species from a single genomic region (like birds, Kerr et al. 2007 or fish, Ward et al. 2005); but that is not the case for plants. In best case scenarios, it is necessary to target several regions (Pennisi 2007; Fazekas et al. 2008), while for taxonomical groups that notably included many tree species, there are still no marker sets available to differentiate species. Finally, the phylogeographic approach identifies the geographic origin of a specimen. It uses genetic markers that show variations between individuals of the same species as well as differences associated with various geographic areas. Major climatic changes, such as those that occurred during the Quaternary glaciation periods, may explain regional differences found within the same species today (Hewitt 2000, 2004). During a glaciation period, species sought protection in places called glacial refugia (Fig. 2), where groups deviated and acquired differences that remain perceptible today, even after recolonization of the area. The ability to capture a phylogeographic signal for a species will depend on several factors: the territory of the species and the presence of physiographic barriers would promote the species' intraspecific differentiation or dispersal capacity, whereas a more mobile species would get distributed more evenly.

\section{Present and potential applications of traceability systems in forestry}

Traceability in forestry production: quality assurance control

In forestry, scientific research has benefited from major investments in genomic projects over the past few years. A recent study has evaluated that more than $\$ 123$ million have been allocated among research projects in forest genomics in Canada (Porth et al. 2015). A significant portion of these funds was used to develop ways, in combination with genomics or not, to increase Canadian forest productivity (e.g., Beaulieu et al. 2014; Park et al. 2016). Combining traditional selection methods with somatic embryogenesis was one of the strategies proposed to increase genetic gains (by more than 20\%), and also to reduce the rotation age of a plantation (by more than 10 years) (Petrinovic et al. 2009; Gélinas and Bull 2013). With a clonal multiplication technique like somatic embryogenesis, it is now possible to channel $100 \%$ of fieldmeasured gain and to reproduce the selected tree (clone) in as many copies as needed. Unfortunately, a human-made error can sometimes jeopardize the expected yield gain: one can easily imagine what could result from the massive propagation of a mislabelled tree that does not have the desired attributes. Therefore, the principle that the origin and identity of a tree can be established all along the production chain is particularly relevant in this modern forestry context where many steps (from the laboratory to the field) are necessary to produce the improved tree. Moreover, such a traceability system 
Fingerprinting

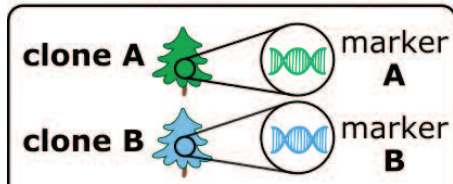

informs about identity

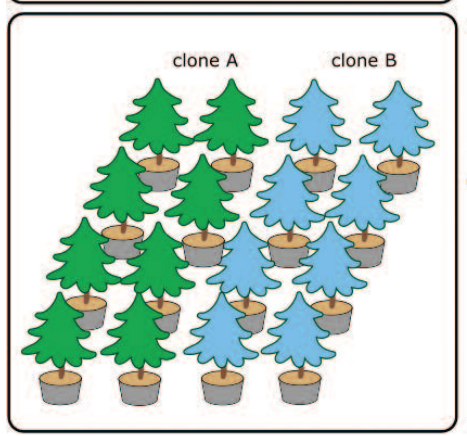

Taxonomy
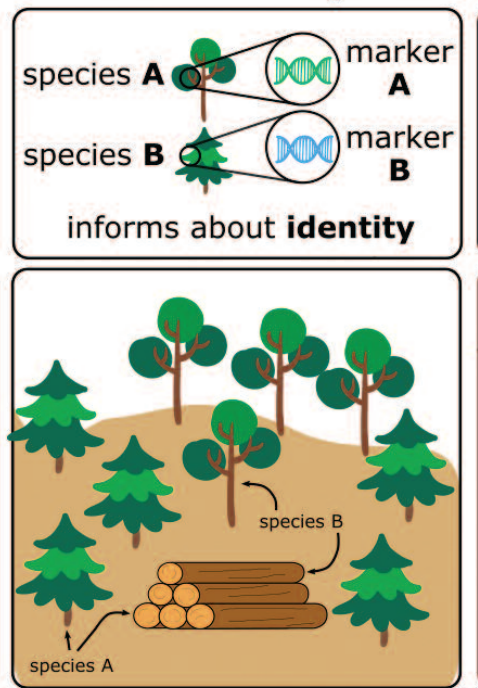

Phylogeography

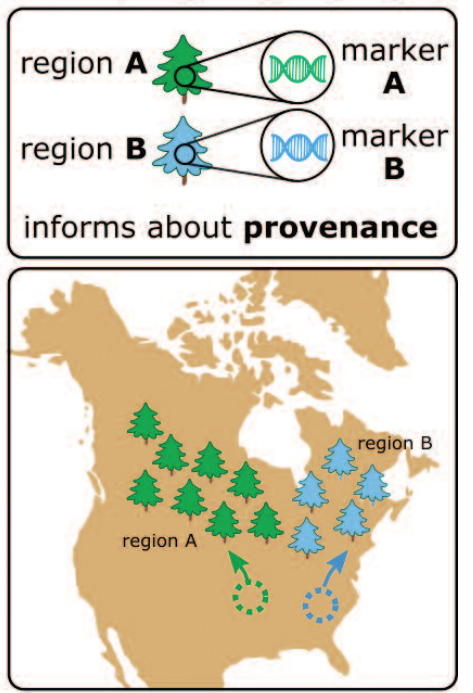

Fig. 2. Representation of the three approaches using genomic tools in a traceability system.

can be seen as an insurance that the expected genetic gain will be obtained at the time of harvesting 35 years after planting.

The tree nursery of St-Modeste (Québec, Canada) has worked to implement a traceability system that uses genetic markers previously developed for white spruce (Pavy et al. 2013). This traceability system project has two objectives (Godbout et al. 2017): 1) to develop methods that make it possible to trace back the origin of the seedling produced (cross of origin); and, 2) to generate a unique genetic fingerprint that could be used to differentiate each embryogenic cell line from the cryobank to the field. Two criteria were also identified: a minimum number of low-cost DNA markers should be used (40 SNPs), and the traceability system (from DNA extraction to data interpretation) should be easy to use by non-specialists. The 40 SNPs corresponded to the capacity of a single Sequenom ${ }^{\circledast}$ genotyping array. Accordingly, this traceability system was developed using simulated data sets and classification methods currently available in the literature. After running computer simulations to generate crosses among elite parent plants for which genomic information was already available, the restricted set of markers was selected without the need to genotype thousands of specimens (i.e., laboratory-produced lines). With this set of markers (36 in total), the nursery of St-Modeste was able to identify the most common sources of error in its white spruce seedling production pipeline. The majority of errors occurred at the time of the controlled crosses, a result that reflects the technique's complexity. This is also in line with previous results from work in similar production systems (Corley 2005; Kumar et al. 2007; Doerksen and Herbinger 2008; Moriguchi et al. 2009; Padi et al. 2015). Most importantly, a unique fingerprint was generated for a majority of the embryogenic cell lines. Finally, although most errors originated at the controlled cross stage, about $25 \%$ of those detected had other and very diverse causes, such as material misidentification or plants being mixed up in the fields or in the cryobanks. Therefore, the propagation of these errors throughout the production line supports the use of a traceability system before the deployment of a reforestation program derived from such production methods.

A traceability system, as described above, is designed to provide information at the time of forest seedling production, but can also be used for the complementary tracing of trees a few years after planting. The ability to trace trees on the ground could alleviate some community concerns about the use of clones in forestry and its impact on genetic diversity in natural forests (Gélinas and Bull 2013; Nilausen et al. 2014).

In France, a traceability system was designed to guarantee the authenticity of the oak used to make wine barrels. The OAKTRACK project developed two sets of genomic tools that could be used independently or together. The first kit was for the identification of oak species (taxonomic approach), while the second confirmed the oak's geographic origin by performing a conformity test to match it with a predicted origin (phylogeographic approach) (Deguilloux et al. 2003; Guichoux et al. 2011; Guichoux and Petit 2014). The OAKTRACK project's objectives were to develop antifraud tools and to improve the quality of the wood being used by optimizing procurement controls. By using the method upstream, managers were able to guarantee the conformity of the species and/or the geographic origin of the logs being sold. Downstream, oenologists can value the information obtained from the identification of the oak species to select for the aromatic potential of the wood being used for the maturation of the wine and other alcohol products. Actually, this service is offered to the community of oenologists. Specialists respond on a case by case basis according to identification needs. Currently, the limitations of the method relate to the state and age of barrel timbers that do not always allow quality DNA extraction. 
Tracking exotic alleles from plantations to natural populations for forest certification

In Canada, the use of exotic species has quickly become an element of forest management and production (Derbowka et al. 2012). Fast-growing trees, such as interspecific hybrid poplar or larch varieties containing exotic components, are integrated in short-term rotation plantations for intensive production purposes. Their use into this context responds to economic, social and environmental demands. Moreover, such intensive silvicultural techniques on small tracts of land may help to reduce the impact of harvesting pressure on the larger areas under ecosystemic management.

Forest certification organizations in Canada (FSC, SFI or CSA) point to a particular concern with the use and planting of exotic species (Morissette 2002). For example, the Forest Stewardship Council (FSC) standard, which dictates a set of sustainable forest management criteria, states that: "the Organization shall only use alien species when knowledge and/or experience have shown that any invasive impacts can be controlled and that effective mitigation measures are in place" (Principle 10.3 in FSC 2015). To be certified, companies must demonstrate that any exotic species of interest when established in plantations is not invasive in order to limit its ecological impact. Forestry companies have limited means (e.g., technical tools and expertise) to measure the risk of potential "invasiveness" of exotic species posed to the environment. In the case of exotic poplars or larches, invasiveness may be observed through the off-plantation establishment of new individuals caused by clonal propagation (cuttings or suckers) or seed dispersion. Invasiveness can also be the result of hybridization between compatible exotic and indigenous species, which will result in new individuals presenting some exotic components.

The use of genomic tools for traceability purposes makes it possible to identify and monitor selected varieties deployed in commercial plantations and to measure putative gene exchange (referred to as genetic pollution) between the socalled exotic species and the indigenous species (Meirmans et al. 2007; Talbot et al. 2011). Recently, molecular tools were developed to characterize trees that would either result from the dispersion of exotic species or their hybridization with native species in surrounding environments (Isabel et al. 2013). These tools consist of a limited set of genetic markers that identify the different species used as well as their hybrids. Hundreds of reference samples from provenance trials, herbaria or directly collected in the field were tested to develop this assay. A sampling and laboratory protocol was also developed to quantify and localize exotic individuals or components resulting from hybridization (e.g., Talbot et al. 2012; Roe et al. 2014). Such a method becomes an efficient way for companies to comply with forest certification standards by providing a precise measure of the invasiveness of the exotic species introduced into their plantations. Moreover, the localization and quantification of exotic gene dispersion improve the targeting and effectiveness of potential mitigation initiatives (Talbot et al. 2012; Meirmans et al. 2014). In poplars, the use of these molecular tools showed that the extent of exotic gene dispersion from plantations with exotic components depends on the recipient native species, the gender of novel varieties used for plantations, the size of natural surrounding native populations, and the environment in which they are found. For instance, disturbed habitats (e.g., near-urban locations) appear more prone to exotics establishment than natural ones (Meirmans et al. 2010; Thompson et al. 2010). Moreover, male poplar varieties should be preferred to female trees since the exotic pollen coming from plantations is diluted in the native pollen cloud (Talbot et al. 2012; LeBoldus et al. 2013). Indeed these tools have helped demonstrate that effective monitoring and risk assessment is imperative to ensure that plantations with exotics do not threaten the genetic integrity of native forest trees or Canada's forest certification.

\section{Urban forestry: resilient and well-adapted trees}

From the time the term "urban forestry" was first introduced in 1974 (Jorgensen 1974), this specialized field of forestry has taken on increasing importance. In Canada, more than $80 \%$ of the population lives in urban areas (Statistics Canada 2011). Over the past few decades, research in urban forestry has shown the many benefits of trees in urban settings, for aesthetic, ecological, economic, social, and public health reasons (Tyrväinen et al. 2005). Moreover, and in a somewhat broader context, urban planners now integrate the concepts of green infrastructure, and valuation of ecological goods and services provide by trees in urban areas. Several Canadian cities have recently adopted urban forestry plans that set standards and management strategies to be applied in their territories (Ordóñez and Duinker 2013).

Tree selection in urban areas is based on several practical criteria (e.g., appearance, seed or pollen production, available space, soil conditions, native species) that differ among the various stakeholders (architects, managers, foresters, citizens, and nursery operators) (Conway and Vander Vecht 2015). Nevertheless, in spite of these differences, one may observe great redundancy in the species/varieties chosen for planting (Bourne and Conway 2014). This can be explained by the stringency of selection criteria related to urban stresses and constraints as well as by the lack of research or breeding programs aimed at developing new tree varieties. As an example of these constraints, we can mention the requirements for contractors to guarantee the survival of planted stock for some stipulated period of time (e.g., two years), which results in extremely conservative approaches when it comes to species choices. With diseases decimating and currently killing thousands of trees in urban forests, experts are calling for the selection of more diversified species (at both the taxonomical and functional levels; Paquette 2016).

Another criterion that can be identified in urban development plans is the prioritization of indigenous species (Ordóñez and Duinker 2013). This common preference reflects the desire to preserve local biodiversity (Almas and Conway 2016). It can also be explained by the fact that local species use local resources more efficiently and are more likely to support the biodiversity of native animal species (McKinney 2002; Burghardt et al. 2009). However, to ensure that the expected benefits of indigenous trees translate into real benefits, they need to be well-adapted to the environment where they are planted; for instance, they have to come from the appropriate hardiness zone. Still, the native character of a species does not guarantee these benefits as tree species distributions often encompass large territories. For example, in a recent study, professionals in the City of Toronto's urban 
Several types of data, in addition to genomic data, are currently available for economically important forest tree species in Canada. These data could be used to create a traceability system based on mixed data that could produce a "Protected Designation of Origin (PDO-like) certification system" to achieve rapid and efficient identification of timber and wood products in Canada. In comparison to conventional forest certification, the focus is put on the origin of the product rather than wood harvesting processes. In addition, such a controlled designation of origin implies a close link between the product, the terroir and the know-how of the artisan. By doing so, not only could a PDO-like label hamper illegal logging, it could also significantly help the expansion of new markets, especially with highly-valuable products. Indeed, very prestigious brands of highly-valuable products have addressed this issue by providing consumers a high-quality standard designation (e.g., for wines, cheese but also oils, and even meat: in the province of Québec, the "Agneau de Charlevoix" was the first meat product to receive a reserved designation (BNQ 8015-900). In the case of wood products, this could be applied to particular attributes that confer significant value to wood, e.g., acoustic (for the manufacture of musical instruments), mechanical or aesthetic qualities.

The establishment of a close relationship between the environment in which a tree has grown and its wood quality could be achieved by drawing on the various data that have been gathered over decades of forestry research. We can hypothesize that the juxtaposition of many types of data would significantly increase the power of resolution necessary to identify the specific signature of a wood sample that would be representative of its environment of origin. Such resolution could be reached through the connection of several databases and the power of algorithms that could identify the right combination to obtain the most informative data (e.g., artificial neural network).

White spruce could constitute the first candidate to test the possibility of identifying such a PDO-like signature; first, because it is of major economic importance in Canada, and second, because incidentally, very large quantity of data is already available. When considering all the potentially useful types of data available from diverse databases and projects for Canadian forest tree species (Fig. 3), we can roughly estimate that more than $50 \%$ of the data concern white spruce.

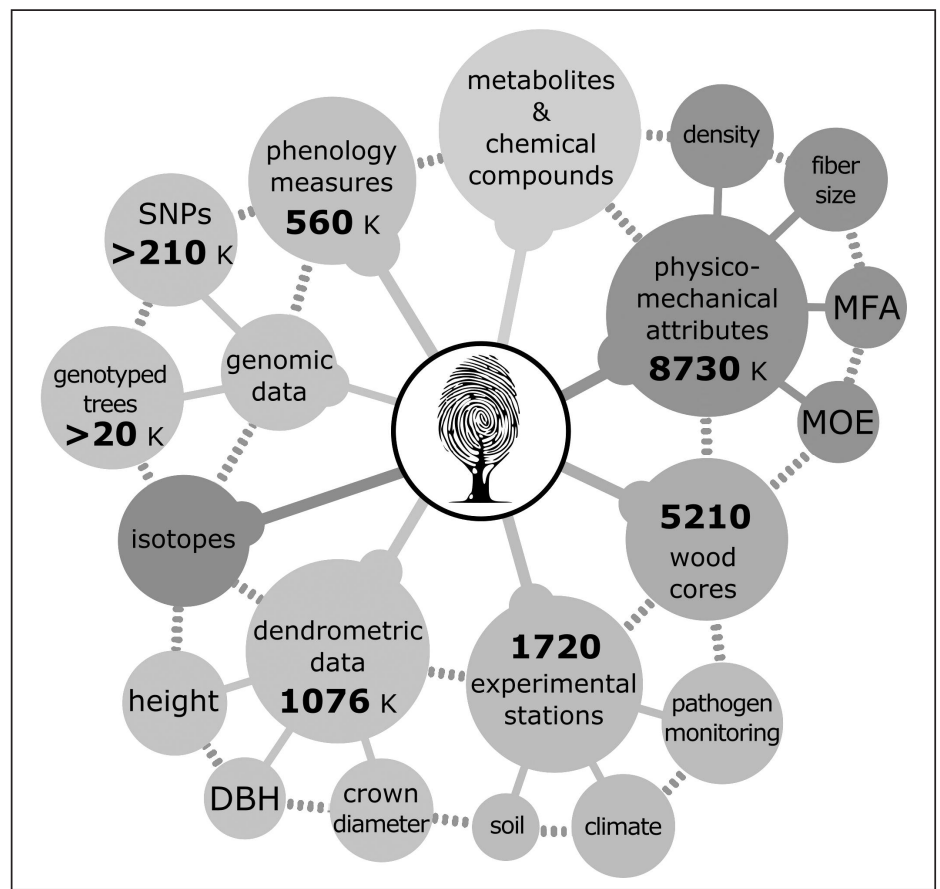

Fig. 3. Representation of different families of data potentially useful to constitute a PDOlike label for a Canadian forest species (nonexhaustive). Bold numbers correspond to the number of items when available for each category found in TREESOURCE (Canada's national database on wood and tree quality developed by NRCan and available to the forest sector: governments, university and industry) for all data, with the exception of genomic data which are available in GenBank (publicly available and managed by NCBI) and also from previous large-scale genomic Canadian projects in the field of forestry. Datasets joined by full lines are from same categories, and dashed lines represent potential connections that could be made in order to constitute a significant signature of environment or provenance. DBH: Diameter at breast height; MFA: Microfibril angle; MOE: Modulus of elasticity; SNPs: Single nucleotide polymorphisms.

forestry unit mention that they do not have the means to verify that the trees they bought come from the right climatic zones (Conway and Vander Vecht 2015). They explain that if local nurseries cannot meet the demand, plants are sometimes procured from U.S. nurseries located farther south which provide plants that are ill-adapted to northern climatic conditions. As a result, while indigenous, these plants will be planted outside of their hardiness zone, so they will be more sensitive to various urban stresses (dry conditions, pathogens, wind, salt, soil compaction) and their survival rate will be reduced. Such maladaptation could therefore translate into significant costs for cities.

Linking these issues and traceability principles indicates that these last ones could potentially serve the different actors and users of urban forestry. Indeed, it highlights the fact that there is a need to a greater taxonomic and functional diversity in urban forestry and that there is a cost to plant the wrong tree at the wrong place. Here we suggest that the different 
approaches using genomic tools presented in this article could help to address some of those issues in urban forestry. For example, the use of genomic tools may appear useful when cities purchase large quantities of plants for large-scale urban developments, i.e., in particular situations when young trees may be difficult to be identified using classical morphology. A taxonomic identification approach could then be used to verify the species, varieties or cultivars. Application of the principle of traceability to urban forestry could also be used to assess provenances in order to ensure that the specimens being planted are of local origin and are therefore adapted to local climatic conditions. To our knowledge, such a phylogeographic approach does not exist in practice and it could certainly be applied to horticultural tree species, but it would need to be preceded by a phase of research and development. Nonetheless, the development of a system for horticultural tree species would require the same methodology as for forest tree species traded on international markets (see below).

Taxonomic identification tools could also be used to monitor pests and diseases in urban areas in order to identify the most (and least) susceptible trees to better inform management and future developments. A better understanding of the genetic diversity of trees (i.e., the hosts) affected by biotic and abiotic stresses could also lead to a better understanding of the evolution of new diseases as soon as the first symptoms appear. Indeed, a better characterization of the host would complement the traditional phytopathological approach that focuses mainly on the pathogen. This could facilitate the identification of species, cultivars, and specimens with higher tolerance or even, in some cases, resistance.

Other evidence emerging from the scientific literature in urban forestry is that such traceability systems should be developed and applied in close collaboration with nurseries that supply trees for urban purposes. Ultimately, the selection of trees for planting often depends on their availability in the nurseries. At present, the needs of cities when selecting trees to fulfil their management plans do not necessarily match the nurseries' available stocks (Sydnor et al. 2010). It is also worth mentioning that nursery stock management is based on client demand, while client choice will also depend on the species available in nurseries (Conway and Vander Vecht 2015). These dynamics, which are not conducive to stock diversification, should be broken by nursery involvement in projects related to the origin or taxonomic identification of trees for urban forestry. It should also be proposed that governmental forest science research departments, which are currently mainly focused on boreal tree species, could take part in the research associated with the development of new varieties that are better adapted to urban environments.

\section{Illegal timber: market and imports}

The need for traceability in the case of wood products arises most commonly in the context of international trade. Canada is a signatory to the Convention on International Trade in Endangered Species of Wild Fauna and Flora (CITES). Under the terms of this agreement, Canada adopted in 1992 its own domestic legislation, the Wild Animal and Plant Protection and Regulation of International and Interprovincial Trade Act (WAPPRIITA). According to this act, it is illegal to possess, distribute or transport wild plants or animals (or products derived from them) that are threatened with extinction (as per CITES lists), that were obtained illegally in their country of origin, or that threaten Canadian ecosystems. Legislation of somewhat similar purpose was adopted elsewhere in the world: the Lacey Act (amended in 2008) in the U.S., the EU Timber Regulation (2010) in Europe and the Illegal Logging Prohibition Act (2012) in Australia. However, while legislative frameworks have been established to identify specific illegal actions, having access to additional scientific tools would help enforce these laws on the ground.

At present, Canadian customs services are on the front line to intercept these products. The identification of suspicious products starts with the examination of the CITES permit that is required for imported products and on which the name of the forest species must be stated. Environment and Climate Change Canada (ECCC) has produced a guide for customs personnel tasked with wood inspection to help with the quick identification of tropical woods listed by CITES. In the same vein, a guide (CD-ROM) dedicated to timber regulated by CITES has also been developed by the Kew Botanical Gardens (Garrett et al. 2010). This guide contains essential information about permits or international trade patterns. Moreover, the CD-ROM contains a database of photographs of macroscopic characteristics with descriptions and a classification method to identify timber. These guides (mainly for morphological inspections) help with the taxonomic identification of the genus (rarely the species) and, in doubt, customs officers are required to call in ECCC specialists for a more extensive analysis. The anatomical analysis of imported woods may be used in some cases to identify prohibited products. However, this work demands a high degree of scientific expertise and time. Again, having access to genomic-based tools would help customs agents do their job.

Presently, countries and organizations do not use systematically large-scale genomic traceability systems to counter illegal wood trading. There are, however, various small-scale or ad hoc initiatives for the inspection and certification of wood products: DoubleHelix (https.//www.doublehelixtracking.com) is a pioneer in the field. Founded in 2008 in Singapore, the company provides chain-of-custody (supply chain) auditing of wood species from regions where illegal harvesting is a major problem. Through this scientific process, producers can qualify for the Certisource certification, which guarantees the legality of the products to Australian importers. One of DoubleHelix's auditing methods is genomic fingerprinting, where products are sampled at harvest (before export) in plantations or forests where harvesting is legal. Genetic markers are then used to confirm that the trees are the same at the other end of the chain, and that no substitution was observed for these genetically-checked batches. This method of fingerprinting using microsatellite markers is now available for merbau (Intsia spp.), a commercially important wood in Indonesia (Lowe et al. 2010). Another method using SNP markers is presently being developed for Indonesian teak (Tectona grandis L. f.) destined to the Australian market (Lowe et al. 2015). According to a group of experts, this method of individual genomic identification is more suitable for species of very high economic value where the volumes harvested are rather low (Lowe et al. 2016). In a legal context, genomic fingerprint methods have also been used to identify: 1) stolen bigleaf maple (Acer macrophyllum Pursh.) wood from the protected Gifford Pin- 
chot National Forest in the State of Washington (U.S.); and, 2) red cedar (Thuja plicata D. Don) wood from Carmanah Walbran Provincial Park on Vancouver Island (Canada). In these two cases, genomic markers previously developed for those species (White et al. 2000, Jardine et al. 2015) were used as forensic tools to verify the origin of the wood. Concerning the bigleaf maple wood, it allowed for the prosecution of the poachers (Goldfarb 2017).

Phylogeographic approaches using genomic tools were also punctually developed and used to identify the geographic origin of timber, such as in the case of merbau (DoubleHelix 2011) or for the Malaysian Neobalanocarpus heimii King P. Ashton (Tnah et al. 2010). Likewise, similar studies, for which the first objective was not to track illegal logging, could serve as a starting point to develop traceability systems, as for the economically important tropical wood of Kapok (Ceiba pentrandra (L.) Gaertn.) (Dick et al. 2007) or Carapa (Carapa guianensis Aubl.) (Cloutier et al. 2005). Most of those ongoing projects concern tropical species, but the same methods and approaches could potentially be applied to Canadian native species for which the geographical structure has been previously studied, such as black spruce (Jaramillo-Correa et al. 2004; Gérardi et al. 2010), jack pine (Godbout et al. 2005, 2010, 2012) or lodgepole pine (Godbout et al. 2008). Indeed, the application of traceability systems to counter the import of illegal exotic wood is currently the subject of most of the studies and development efforts because the needs are great. That being said, the challenges are also significant, notably because the species and territories targeted may be difficult to access and little is actually known about most of those exotic species.

While there is currently no requirement for Canada to guarantee a "local" origin for its export-oriented wood products, such tools may become necessary in future as it would increase the ability to legally guarantee the Canadian origin of our products to our trading partners. Indeed, the absence of a traceability system could eventually lead importing countries to suspect extraterritorial origins for our wood products; they could also suspect that Canada is acting as a mere transit point in order to "launder" illegal goods. Furthermore, a traceability system that authenticates the wood's local origins could pave the way for the implementation of a "Made in Canada" label for wood products sold on domestic markets. According to a recent study, consumers see value in local origins when they shop for wood products, particularly for value-added products (Chamberland et al. 2016).

\section{Perspectives and Challenges}

All the examples presented in this report face the same two major challenges: applicability and databases. In both cases, these challenges involve technical (or technological) aspects as well as socioeconomic aspects.

\section{The applicability challenge}

The primary and obvious first question that may challenge the development and the use of a genomic-based traceability system is certainly: "How much does it cost?" Our aim here was not to discuss in depth this complex aspect since it is context dependent. In fact, multiple factors should be examined. Among them the choice of markers technology, which in turn depends on $\mathrm{i}$ ) the material (solid wood products, $2^{\text {nd }}$ trans- formation products) to be tested; ii) where and by whom the analyses will be conducted; iii) how fast the results will be required (minutes vs hours vs days); and, iv) for which purposes (legality and prosecution or sustainability and principles). It is also worth to take into account the risk that the chosen technology will become obsolete after a certain period of time. Indeed, we observe a rapid turnover of these technologies. Depending on the scale at which the traceability system will be applied, the question of dealing with an external genomic platform or to develop in-house genomic resources (i.e., equipment and expertise) should also be evaluated. Over the last decade, the cost of sequencing and genotyping have considerably decreased, and we can expect that this trend will continue. New technologies are still to come in this area. Following these complex considerations, it clearly appears that the decision to develop a traceability system or not will likely be make on a case-by-case basis. Still, economic scenarios to help decision makers should consider and include the cost of doing nothing. Hence, pilot studies based on the use of different tools should be developed to help answer these socio-economic considerations.

Any traceability system using genomic-based tools necessarily involves DNA extraction. The quality and quantity of DNA extracted will depend on the source material and on the method used. Furthermore, for trees it is easier to extract DNA from fresh material (e.g., leaves, cambium or phloem) than from wood. Compared with other plant tissues, DNA extraction from wood is more arduous because 1) it must be mechanically treated first; 2) it contains chemical compounds that could compromise the quality of the sample extracted; 3 ) the DNA may be degraded by decomposers like fungi or microorganisms; and finally, 4) the DNA may be degraded if it comes from cells that have been dead for some time, depending on how much time has passed since the wood was harvested (Rachmayanti et al. 2009). However, it is possible to adapt extraction protocols to wood, even in the case of processed products such as dried or heat-treated wood (e.g., Deguilloux et al. 2003; Asif and Cannon 2005; Rachmayanti et al. 2006). The choice of protocol must also be adapted to the method of DNA analysis used, since the different techniques will require specific quantities and qualities of DNA. Hence the material to be tested and the quality of DNA that can be expected will limit the choice of genomic technologies and should also be considered in designing the traceability system. The combination of different protocols and analyses should be in line with the degree of uncertainty that will be tolerated by the users. Indeed, this uncertainty will have to be reduced and strictly controlled in cases where the results will be used as legal evidence and must meet forensic identification standards (e.g., ISO 18385 used for human evidence; see Ogden et al. 2009, Ogden 2010 for further details on these important aspects).

The application of a traceability method using genomicsbased tools will also require special expertise from the professionals processing the samples; this varies in importance depending on the technique chosen. In some cases, given the scope of the results, it may be recommended that certified teams apply the protocols. Generally, the need for expertise (in genomics) will be inversely proportional to the possibility of automating the method. Total automatization of the process is, to our knowledge, not actually possible, although promising 
technology research has been performed in the fields of medical diagnostic and forensic science that could be adapted to forestry (Montpetit et al. 2005; Bissonnette and Bergeron 2016). Conservation-based initiatives are also currently being implemented by some organizations (e.g., Conservation X Labs), in collaboration with governments, universities, corporations and NGOs (e.g., WWF), with the goal of developing rapid identification technologies for living material.

A final and essential element to consider for the implementation and development of a traceability system in forestry is the relationship to be established between endusers and scientists. This link is a prerequisite to the creation of a system that will meet the needs of the former while using the technical and scientific skills of the latter. To this end, the development of a project, i.e., determining its objectives, the methods tested and the material to be used, should ideally be done through discussions between both parties. Hence, traceability systems should benefit from the contribution of technical knowledge (the scientists) and practical knowledge (end-users); this "knowledge co-production" (Callon 1999; Pouliot and Godbout 2014) can facilitate the deployment of applications in the field and also encourage their adoption by users.

\section{The database challenge}

The resolving power of a system is intimately linked to the quality of its database. The construction of a database and validation of the data it contains with reference samples form the cornerstone of any traceability project. Not only is it necessary to make sure that the database is rich in information, the information must also be of quality. This means that new data must be inspected before being integrated into the system (Butler 2006; Moore and Kornfield 2011). In certain cases, for instance when the data feed comes from various sources, a curator should ensure that new entries meet a set of predetermined criteria, as it actually is the case for big genomics databases, such as the NCBI's GenBank.

A large amount of data is presently available to constitute forest-traceability databases. They have been mostly generated by forestry science research and also by continuous field monitoring activities (see Box 1 for an example of how these diverse data could be used in a traceability context). Therefore, a preliminary step in the establishment of a traceability system would require an exhaustive inventory of already existing databases (GenBank, TREESOURCE, TreeGenes) to identify and structure the available data that could be useful to develop the genomic tools (i.e., genetic markers) and to identify validated reference specimens. Analysis of this abundant information and its diverse sources calls for expertise from the field of data science which involves the analysis and highlighting of trends in big data. These analyses could also identify the as-yet-unknown or unpresumed capacities of such data to inform on various issues, whether in the field of traceability or other topics.

One other challenge, and not the least in database management, is the notion of open data and ownership. At present, data that were generated by governmental agencies, universities or private enterprises either belong to the public or private domain. This means that before developing a traceability system based on existing data, agreements have to be reached between the various parties to clarify data ownership and access issues. Similarly, the legal framework in which the traceability system will be used must also be established (i.e., cases of patenting or business disputes). Consequently, technical and scientific development will need to be carried out in parallel with the development of a legal framework that will set out the capabilities and limitations of its application.

\section{Conclusions}

Several parameters require consideration in the development and application of a genomics-based traceability system for the Canadian forestry sector, which faces numerous challenges today. Regulations within international markets are currently becoming tougher which could lead to demands for new proofs of identity, safety and/or origin of products destined for export. Domestically, consumers have expanded their purchasing criteria, particularly in relation to sustainability issues (Boivin and Durif 2012). At the same time, the Canadian forest, due to its northern location, is expected to be especially affected by climate change (Price et al. 2013). This will lead to certain practices being modified, such as the use of assisted migration (in natural and urban forests; Aubin et al. 2011), or to the application of new forest management practices to mitigate climate change effects (fire, pathogens, wind; Gauthier et al. 2015).

In Canada, some of these important questions are presently being addressed through regulatory and forest certification systems. However, we think there is still place for the development of complementary tools, such as those presented here, that would assist with mechanisms currently being implemented. One of the easiest ways to implement a traceability method for application to the Canadian forest sector would be to include it within forest certification systems. On the one hand, the new traceability system would benefit from the well-developed framework of the forest certification process. On the other hand, forest certification systems would gain strength and rigour as they would benefit from reproducible technoscientific tools, such as genomic tools.

Whether it is included into forest certification or not, we have demonstrated in this article that the opportunities to develop traceability methods are abundant. Internationally, the community is currently considering technical and conceptual means of answering traceability issues (e.g., via the Society for wildlife forensic science, which brings together international scientists whose interests include issues related to forestry or Forest Legality Initiative that gathers together partners and stakeholders to advance dialogue and initiatives related to the international trade in timber). In Canada, materials, data and expertise in forest genomics are currently available. All that remains to be done is to capitalize on them.

\section{Acknowledgements}

The authors thank Marie-Claude Gros-Louis and Dr. Lise Caron for helpful discussions and support, and Isabelle Lamarre for her thorough revision of the manuscript. This study was funded through a Genomics Research and Development Initiative grant, and funds from the Canadian Wood Fibre Centre to NI. 


\section{References}

Almas, A.D. and T.M. Conway. 2016. The role of native species in urban forest planning and practice: A case study of Carolinian Canada. Urban For. \& Urban Greening 17: 54-62. doi:10.1016/ j.ufug.2016.01.015.

Asif, M.J. and C.H. Cannon. 2005. DNA extraction from processed wood: A case study for the identification of an endangered timber species (Gonystylus bancanus). Plant Mol. Biol. Rep. 23: 185-192. doi:10.1007/BF02772709.

Aubin, I. et al. 2011. Why we disagree about assisted migration: Ethical implications of a key debate regarding the future of Canada's forests. Forest. Chron. 87: 755-765. doi:10.5558/tfc2011-092.

Beaulieu, J., T. Doerksen, S. Clément, J. MacKay and J. Bousquet. 2014. Accuracy of genomic selection models in a large population of open-pollinated families in white spruce. Heredity 113: 343-352. doi:10.1038/hdy.2014.36.

Bernard, A., F. Broeckaert, G. De Poorter, A. De Cock, C. Hermans, C. Saegerman and G. Houins. 2002. The Belgian $\mathrm{PCB} /$ dioxin incident: Analysis of the food chain contamination and health risk evaluation. Environ. Res. 88: 1-18. doi:10.1006/ enrs.2001.4274.

Bissonnette, L. and M.G. Bergeron. 2016. The genePOC platform, a rational solution for extreme point-of-care testing. Micromachines 7: 1-14. doi:10.3390/mi7060094.

Boivin, C. and F. Durif. 2012. Le Baromètre 2012 de la consommation responsable. L'Observatoire de la consommation responsable, Université du Québec à Montréal, Montréal, QC.

Bourne, K.S. and T.M. Conway. 2014. The influence of land use type and municipal context on urban tree species diversity. Urban Ecosyst. 17: 329-48. doi:10.1007/s11252-013-0317-0.

Burghardt, K.T., D.W. Tallamy and W. Gregory Shriver. 2009. Impact of native plants on bird and butterfly biodiversity in suburban landscapes. Conserv. Biol. 23: 219-224. doi:10.1111/j.15231739.2008.01076.x.

Butler, J. 2006. Debunking some urban legends surrounding validation within the forensic DNA community. Profiles DNA 9: 3-6.

Callon, M. 1999. The role of lay people in the production and dissemination of scientific knowledge. Sci. Technol. Soc. 4: 81-94. doi:10.1177/097172189900400106.

Chamberland, V., F. Robichaud and N. Gélinas. 2016. Origin labelling as a differentiation strategy for wood products. In: L. Petruzzellis and R.S. Winer (eds.). Rediscovering the Essentiality of Marketing. pp. 613-626. Springer International Publishing, Cham, Switzerland.

CIVC. 2011. [Comité interprofessionel du vin de Champagne]. Histoire interprofessionnelle de la Champagne. Éléments de chronologie. Vignerons et Maisons de Champagne, Comité interprofessionnel du vin de Champagne, Épernau, France.

Cloutier, D., J.S.R. Póvoa, L.C. Procopio, N.V.M. Leão, L.H.D.O. Wadt, A.Y. Ciampi and D.J. Schoen. 2005. Chloroplast DNA variation of Carapa guianensis in the Amazon basin. Silvae Genet. 54: 270-274.

Conway, T.M. and J. Vander Vecht. 2015. Growing a diverse urban forest: Species selection decisions by practitioners planting and supplying trees. Landsc. Urban Plan. 138: 1-10. doi:10.1016/j.landurbplan.2015.01.007.

Corley, R.H.V. 2005. Illegitimacy in oil palm breeding - A review. J. Oil Palm Res. 17: 64-69.

Deguilloux, M.F., M.H. Pemonge, L. Bertel, A. Kremer and R.J. Petit. 2003. Checking the geographical origin of oak wood: Molecular and statistical tools. Mol. Ecol. 12: 1629-1636. doi:10.1046/j.1365-294X.2003.01836.x.

Derbowka, D.R., S. Andersen, S. Lee-Andersen and C. Stenberg. 2012. Poplar and willow cultivation and utilization in Canada [online]. Poplar and Willow Council of Canada, Edmonton, AB. Available from http://www.poplar.ca/upload/documents/ipccan2012.pdf (accessed 15 May 2017).
Dick, C.W., E. Bermingham, M.R. Lemes and R. Gribel. 2007. Extreme long-distance dispersal of the lowland tropical rainforest tree Ceiba pentandra L. (Malvaceae) in Africa and the Neotropics. Mol. Ecol. 16: 3039-3049. doi:10.1111/j.1365-294X.2007.03341.x.

Doerksen, T.K. and C.M. Herbinger. 2008. Male reproductive success and pedigree error in red spruce open-pollinated and polycross mating systems. Can. J. For. Res. 38: 1742-1749. doi:10.1139/X08-025. Dormontt, E.E. et al. 2015. Forensic timber identification: It's time to integrate disciplines to combat illegal logging. Biol. Conserv. 191: 790-798. doi:10.1016/j.biocon.2015.06.038.

DoubleHelix. 2011. Applied genetics for forest conservation and sustainable trade. The state of DNA technology for trees \& wood products. $28 \mathrm{p}$.

European Parliament. 2002. Regulation (EC) No 178/2002 of the European Parliament and of the Council of 28 January 2002 laying down the general principles and requirements of food law, establishing the European Food Safety Authority and laying down procedures in matters of food safety. Off. J. Eur. Comm. L31: 1-24.

Fazekas, A.J., K.S. Burgess, P.R. Kesanakurti, S.W. Graham, S.G. Newmaster, B.C. Husband, D.M. Percy, M. Hajibabaei and S.C.H. Barrett. 2008. Multiple multilocus DNA barcodes from the plastid genome discriminate plant species equally well. PLoS ONE 3: e2802. doi:10.1371/journal.pone.0002802.

FSC. 2015. [Forest Stewardship Council]. FSC principles and criteria for Forest Stewardship, FSC-STD-01-001 V5-2 EN. Forest Stewardship Council, Bonn, Germany.

Garrett, L., N. McGough, M. Groves and G. Clarke. 2010. CITES and timber: Ramin (+ timber identification CD-ROM). Kew Publishing. London, UK.

Gauthier, S., P. Bernier, T. Kuuluvainen, A.Z. Shvidenko and D.G. Schepaschenko. 2015. Boreal forest health and global change. Science 349: 819-822. doi:10.1126/science.aaa9092.

Gélinas, N. and G. Bull. 2013. Is the application of genomics to growing trees competitive and acceptable? E-lectures Series of the Canadian Institute of Forestry.

Gérardi, S., J.P. Jaramillo-Correa, J. Beaulieu and J. Bousquet. 2010. From glacial refugia to modern populations: New assemblages of organelle genomes generated by differential cytoplasmic gene flow in transcontinental black spruce. Mol. Ecol. 19: 5265-5280. doi:10.1111/j.1365-294X.2010.04881.x.

Gill, P., A.J. Jeffreys and D.J. Werrett. 1985. Forensic application of DNA 'fingerprints'. Nature 318: 577-579. doi:10.1038/318577a0.

Godbout, J., J. Beaulieu and J. Bousquet. 2010. Phylogeographic structure of jack pine (Pinus banksiana; Pinaceae) supports the existence of a coastal glacial refugium in northeastern North America.. Am. J. Bot. 97: 1903-1912. doi:10.3732/ajb.1000148.

Godbout, J., F.C. Yeh and J. Bousquet. 2012. Large-scale asymmetric introgression of cytoplasmic DNA reveals Holocene range displacement in a North American boreal pine complex. Ecol. Evol. 2: 1853-1866. doi:10.1002/ece3.294.

Godbout, J., J.P. Jaramillo-Correa, J. Beaulieu and J. Bousquet. 2005. A mitochondrial DNA minisatellite reveals the postglacial history of jack pine (Pinus banksiana), a broad-range North American conifer. Mol. Ecol. 14: 3497-3512. doi:10.1111/j.1365-294X. 2005.02674.x.

Godbout, J., A. Fazekas, C.H. Newton, F.C. Yeh and J. Bousquet. 2008. Glacial vicariance in the Pacific Northwest: evidence from a lodgepole pine mitochondrial DNA minisatellite for multiple genetically distinct and widely separated refugia. Mol. Ecol. 17: 2463-2475.

Godbout, J., L. Tremblay, C. Levasseur, P. Lavigne, A. Rainville, J. Mackay, J. Bousquet and N. Isabel. 2017. Development of a traceability system based on SNP array for large-scale production of highvalue white spruce (Picea glauca). Front. Plant Sci. 8: 1264. doi:10.3389/fpls.2017.01264. 
Goldfarb, B. 2017. Busting the tree ring: How a landmark investigation unraveled a Washington timber-poaching gang. High Country News, March 20, 2017. Available from http://www.hcn.org/issues/ 49.5/busting-the-tree-ring

Guichoux, E. and R.J. Petit. 2014. Déclaration d'invention auprès de l'INPI : Méthode de traçabilité géographique des bois de chêne. Brevet d'invention $n^{\circ}$ DI-RV-13-00566.

Guichoux, E., L. Lagache, S. Wagner, P. Léger and R.J. Petit. 2011. Two highly validated multiplexes (12-plex and 8-plex) for species delimitation and parentage analysis in oaks (Quercus spp.). Mol. Ecol. Resour. 11: 578-585. doi:10.1111/j.1755-0998.2011.02983.x.

Hajibabaei, M., G.A.C. Singer, P.D.N. Hebert and D.A. Hickey. 2007. DNA barcoding: How it complements taxonomy, molecular phylogenetics and population genetics. Trends Genet. 23: 167-172. doi:10.1016/j.tig.2007.02.001

Hewitt, G. 2000. The genetic legacy of the Quaternary ice ages. Nature 405: 907-913. doi:10.1038/35016000.

Hewitt, G.M. 2004. Genetic consequences of climatic oscillations in the Quaternary. Philos. Trans. R. Soc. Lond. B 359: 183-195. doi:10.1098/rstb.2003.1388.

Isabel, N., M. Lamothe and S.L. Thompson. 2013. A second-generation diagnostic single nucleotide polymorphism (SNP)-based assay optimized to distinguish among eight poplar (Populus L.) species and their early hybrids. Tree Genet. Genomes 9: 621-626. doi:10.1007/s11295-012-0569-5.

ISO. 1994. [International Organization for Standardization]. Quality management and quality insurance - Vocabulary. ISO/TC 176/SC 1, Geneva, Switzerland.

Jaramillo-Correa, J.P., J. Beaulieu and J. Bousquet. 2004. Variation in mitochondrial DNA reveals multiple distant glacial refugia in black spruce (Picea mariana), a transcontinental North American conifer. Mol. Ecol. 13: 2735-2747. doi:10.1111/j.1365-294X.2004.02258.x. Jardine, D.I., E.E. Dormontt, K.-J. van Dijk, R.R.M. Dixon, B. Dunker and A.J. Lowe. 2015. A set of 204 SNP and INDEL markers for bigleaf maple (Acer macrophyllum Pursch). Conserv. Genet. Resour. 7: 797-801. doi:10.1007/s12686-015-0486-7.

Jeffreys, A.J., V. Wilson and S.L. Thein. 1985. Individual-specific 'fingerprints' of human DNA. Nature 316: 76-79. doi:10.1038/ $315279 \mathrm{a} 0$.

Jeffreys, A.J., V. Wilson, R. Neumann and J. Keyte. 1988. Amplification of human minisatellites by the polymerase chain reaction: Towards DNA fingerprinting of single cells. Nucleic Acids Res. 16: 10953-10971.

Jorgensen, E. 1974. Towards an urban forestry concept. In: Proceedings of the 10th Commonwealth Forestry Conference. Commonwealth Forestry Association, Craven Arms, Shropshire, UK.

Kerr, K.C.R., M.Y. Stoeckle, C.J. Dove, L.A. Weigt, C.M. Francis and P.D.N Hebert. 2007. Comprehensive DNA Barcode coverage of North American Birds. Mol. Ecol. Notes, 7, 535-543. doi: 10.1111/ j.1471-8286.2006.01670.x.

Khaksar, R., T. Carlson, D.W. Schaffner, M. Ghorashi, D. Best, S. Jandhyala, J. Traverso and S. Amini. 2015. Unmasking seafood mislabeling in U.S. markets: DNA barcoding as a unique technology for food authentication and quality control. Food Control 56: 71-76. doi:10.1016/j.foodcont.2015.03.007.

Kumar, S., S. Gerber, T.E. Richardson and L. Gea. 2007. Testing for unequal paternal contributions using nuclear and chloroplast SSR markers in polycross families of radiata pine. Tree Genet. Genomes 3: 207-214. doi:10.1007/s11295-006-0056-y.

LeBoldus, J.M., N. Isabel, K.D. Floate, P. Blenis and B.R. Thomas. 2013. Testing the "hybrid susceptibility" and "phenological sink" hypotheses using the $P$. balsamifera - $P$. deltoides hybrid zone and septoria leaf spot [Septoria musiva]. PloS ONE, 8: p.e84437. doi:10.1371/journal.pone.0084437

Logan, C.A., S.E. Alter, A.J. Haupt, K. Tomalty and S.R. Palumbi. 2008. An impediment to consumer choice: Overfished species are sold as Pacific red snapper. Biol. Conserv. 141: 1591-1599. doi:10.1016/j.biocon.2008.04.007.
Lowe, A., E. Dormontt and A. Rimbawanto. 2015. Proof on concept: Verification of chain of custody of teak in Indonesia using DNA markers. Austral. Cent. Intl. Agric. Res. Final Rep. FR2015-15.

Lowe, A.J., K.-N. Wong, Y.-S. Tiong, S. Iyerh and F.-T. Chew. 2010. A DNA method to verify the integrity of timber supply chains: Confirming the legal sourcing of merbau timber from logging concession to sawmill. Silvae Genet. 59: 263-268.

Lowe, A.J. et al. 2016. Opportunities for improved transparency in the timber trade through scientific verification. BioScience 66: 990-998. doi:10.1093/biosci/biw129.

McKinney, M.L. 2002. Urbanization, biodiversity, and conservation. BioScience 52: 883-890. doi:10.1641/0006-3568(2002)052[0883: UBAC]2.0.CO;2.

Meirmans, P.G., M. Lamothe, P. Périnet and N. Isabel. 2007. Species-specific single nucleotide polymorphism markers for detecting hybridization and introgression in poplar. Can. J. Bot. 85: 1082-1091. doi:10.1139/B07-069.

Meirmans, P.G., M.C. Gros-Louis, M. Lamothe, M. Perron, J. Bousquet and N. Isabel. 2014. Rates of spontaneous hybridization and hybrid recruitment in co-existing exotic and native mature larch populations. Tree Genet. Genomes 10: 965-975. doi:10.1007/ s11295-014-0735-z.

Meirmans, P.G., M. Lamothe, M.-C. Gros-Louis, D. Khasa, P. Périnet, J. Bousquet and N. Isabel. 2010. Complex patterns of hybridization between exotic and native North American poplar species. Am. J. Bot. 97: 1688-1697. doi:10.3732/ajb.0900271.

Montpetit, S.A., M.S.F.S., I.T. Fitch and P.T. O'Donnell. 2005. A simple automated instrument for DNA extraction in forensic casework. J. Forensic Sci. 50: 1-9.

Moore, K.M. and I.L. Kornfield. 2011. Best practices in wildlife forensic DNA. In: J.E. Huffman and J.R. Wallace (eds.). Wildlife forensics: methods and applications. pp. 201-236. Wiley-Blackwell, Chichester, UK

Moriguchi, Y., D. Ishiduka, T. Kaneko, S. Itoo, H. Taira and Y. Tsumura. 2009. The contribution of pollen germination rates to uneven paternity among polycrosses of Cryptomeria japonica. Silvae Genet. 58: 139-144.

Morissette, S. 2002. Is forest certification compatible with fastgrowing plantations? Information Notice, Réseau Ligniculture Québec, Québec, QC.

NRCan. 2017. [Natural Resources Canada]. Forest certification in Canada. [online] Available from http://www.nrcan.gc.ca/forests/ canada/certification/17474. [accessed 28 July 2017].

Nilausen, C., N. Gélinas and G. Bull. 2014. Proposed research on social perception of marker-assisted selection and its role in the forests of British Columbia. Forest. Chron. 90: 666-669.

Ogden, R. 2010. Forensic science, genetics and wildlife biology: Getting the right mix for a wildlife DNA forensics lab. Forensic Sci. Med. Pathol. 6: 172-179. doi:10.1007/s12024-010-9178-5.

Ogden, R., N. Dawnay and R. McEwing. 2009. Wildlife DNA forensics - bridging the gap between conservation genetics and law enforcement. Endanger. Species Res. 9: 179-195. doi:10.3354/ esr00144.

Ordóñez, C. and P.N. Duinker. 2013. An analysis of urban forest management plans in Canada: Implications for urban forest management. Landsc. Urban Plan. 116: 36-47. doi:10.1016/j.landurbplan.2013.04.007.

Padi, F.K., A. Ofori, J. Takrama, E. Djan, S.Y. Opoku, A.M. Dadzie, R. Bhattacharjee, J.C. Motamayor and D. Zhang. 2015. The impact of SNP fingerprinting and parentage analysis on the effectiveness of variety recommendations in cacao. Tree Genet. Genomes 11 : 44. doi:10.1007/s11295-015-0875-9.

Paquette, A. 2016. Repenser le reboisement. Guide stratégique pour l'augmentation de la canopée et de la résilience de la forêt urbaine de la région métropolitaine de Montréal. Cornelia Garbe, Jour de la Terre, Montréal, QC.

Park, Y.-S., J. Beaulieu and J. Bousquet. 2016. Multi-varietal forestry integrating genomic selection and somatic embryogenesis. 
In: Y.-S. Park, J. Bonga and H.K. Moon (eds). Vegetative Propagation of Forest Trees. pp. 302-322. National Institute of Forest Science, Seoul, Korea.

Pavy, N. et al. 2013. Development of high-density SNP genotyping arrays for white spruce (Picea glauca) and transferability to subtropical and nordic congeners. Mol. Ecol. Resour. 13: 324-336. doi:10.1111/1755-0998.12062.

Pennisi, E. 2007. Wanted: A barcode for plants. Science 318: 190-191. doi:10.1126/science.318.5848.190.

Petrinovic, J.F., N. Gélinas and J. Beaulieu. 2009. Benefits of using genetically improved white spruce in Quebec: The forest landowner's viewpoint. Forest. Chron. 85: 571-582. doi:10.5558/ tfc85571-4.

Porth, I., G. Bull, S. Ahmed, Y.A. El-Kassaby and M. Boyland. 2015. Forest genomics research and development in Canada: Priorities for developing an economic framework. Forest. Chron. 91: 60-70. doi:10.5558/tfc2015-011.

Pouliot, C. and J. Godbout. 2014. Thinking outside the 'knowledge deficit' box. EMBO Rep. 15: 833-835. doi:10.15252/embr.201438590.

Price, D.T. et al. 2013. Anticipating the consequences of climate change for Canada's boreal forest ecosystems. Environ. Rev. 21: 322-365. doi:10.1139/er-2013-0042.

Rachmayanti, Y., L. Leinemann, O. Gailing and R. Finkeldey. 2006. Extraction, amplification and characterization of wood DNA from Dipterocarpaceae. Plant Mol. Biol. Rep. 24: 45-55. doi:10.1007/BF02914045.

Rachmayanti, Y., L. Leinemann, O. Gailing and R. Finkeldey. 2009. DNA from processed and unprocessed wood: Factors influencing the isolation success. Forensic Sci. Int. Genet. 3: 185-192. doi:10.1016/j.fsigen.2009.01.002.

Ratnasingham, S. and P.D.N. Hebert. 2007. BOLD : The Barcode of Life Data System (www.barcodinglife.org). Mol. Ecol. Notes 7: 355-364. doi:10.1111/j.1471-8286.2006.01678.x.

Roe, A.D., C.J.K. MacQuarrie, M.-C. Gros-Louis, J.D. Simpson, J. Lamarche, T. Beardmore, S.L. Thompson, P. Tanguay and N. Isabel. 2014. Fitness dynamics within a poplar hybrid zone: II. Impact of exotic sex on native poplars in an urban jungle. Ecol. Evol. 4: 1876-1889. doi:10.1002/ece3.1028

Statistics Canada. 2011. Canada's rural population since 1851. Statistics Canada Catalogue. Ottawa, ON. No. 98-310-X2011003.
Sydnor, T.D., S. Subburayalu and M. Bumgardner. 2010. Contrasting Ohio nursery stock availability with community planting needs. Arboric. Urban For. 36: 47-54.

Talbot, P., S.L. Thompson, W. Schroeder and N. Isabel. 2011. An efficient single nucleotide polymorphism assay to diagnose the genomic identity of poplar species and hybrids on the Canadian prairies. Can. J. For. Res. 41: 1102-1111. doi:10.1139/x11-025.

Talbot, P., W. Schroeder, J. Bousquet and N. Isabel. 2012. When exotic poplars and native Populus balsamifera L. meet on the Canadian Prairies: Spontaneous hybridization and establishment of interspecific hybrids. For. Ecol. Manag. 285: 142-152. doi:10.1016/ j.foreco.2012.07.036.

Thompson, S.L., M. Lamothe, P.G. Meirmans, P. Périnet and N. Isabel. 2010. Repeated unidirectional introgression towards Populus balsamifera in contact zones of exotic and native poplars. Mol. Ecol. 19: 132-145. doi:10.1111/j.1365-294X.2009.04442.x.

Tnah, L.H., S.L. Lee, K.K.S. Ng, Q.Z. Faridah and I. FaridahHanum. 2010. Forensic DNA profiling of tropical timber species in Peninsular Malaysia. For. Ecol. Manage. 259: 1436-1446. doi:10.1016/j.foreco.2010.01.017.

Tyrväinen, L., S. Pauleit, K. Seeland and S. de Vries. 2005. Benefits and uses of urban forests and trees. In: C.C. Konijnendijk, K. Nilsson, T.B. Randrup and J. Schipperijn (eds.). Urban forests and trees: A reference book. pp. 81-114. Springer-Verlag, Berlin, Germany.

UN Global Compact and BSR. 2014. A guide to traceability. A practical approach to advance sustainability in global supply chains. United Nations Global Compact, New York, NY.

Wales, C., M. Harvey and A. Warde. 2006. Recuperating from BSE: The shifting UK institutional basis for trust in food. Appetite 47: 187-195. doi:10.1016/j.appet.2006.05.007.

Ward, R.W., T.S. Zemlak, B.H. Innes, P.R. Last and P.D.N. Hebert. 2005. DNA barcoding Australia's fish species. Philos. Trans. Royal Soc. B, 360, 1847-1857.

White, E., J. Hunter, C. Dubetz, R. Brost, A. Bratton, S. Edes and R. Sahota. 2000. Microsatellite markers for individual tree genotyping: Application in forest crime prosecutions. J. Chem. Technol. Biotechnol. 75: 923-926. doi:10.1002/1097-4660(200010)75:10< 923::AID-JCTB309>3.0.CO;2-S. 